\title{
Energy consumption and greenhouse gases emissions on relation Brno - Jihlava
}

\author{
Vladimír Lupták ${ }^{1^{*}}$ Martina Hlatká ${ }^{1}$ and Rudolf Kampf ${ }^{1}$ \\ ${ }^{1}$ Institute of Technology and Business in České Budějovice, Okružní 517/10, 37001 České Budějovice, Czech Republic.
}

\begin{abstract}
Currently, the influence of transport on the environment represents a serious problem, especially in terms of energy consumption and generation of gases causing global warming. The contribution on the topic of comparing energy consumption and greenhouse gases emissions on relation Brno - Jihlava thus aims to describe generation of emissions in the current types of transport and their calculation according to EN 16258:2012. The results of the calculations will be expressed in emission intensity units to the number of passengers transported. The EN 16258:2012 calculations will be applied to passenger rail transport. In particular, energy intensity and generation of greenhouse gases will be monitored in relation to travelling the distance between Brno and Jihlava.
\end{abstract}

\section{Introduction}

Transport and transportation of either material or passengers currently plays an important role in many aspects of our lives. Due to the increasing number of means of transport, a long-term strategy and the role of the railway sector in a national economy and transnational ecology context are very important. In recent years, there has been a significant increase in oil consumption and exhaust gases emissions. The impact of transport is clearly visible also in the landscape affected by land take and construction activities associated with repairs or construction of railway lines. The most discussed topic, however, is the impact of exhaust gases and the pollutants contained on the environment and human health. The problem of the influence of pollutants from exhaust gases on human health is even more significant in urban agglomerations, where their concentration is up to 100 times higher than in uninhabited areas. The need to starting a political fight against transport emission generation is even more urgent due to the upward global warming trend, which is caused predominantly by greenhouse gases, their main producer being transport. Transport is reported to emit about $23 \%$ of all anthropogenic $\mathrm{CO}_{2}$ production on Earth. [1-3]

The contribution is focused on this negative aspect of transport and will try to compare two modes of transport on the aforementioned transport relation so that it is possible to better understand all side effects and burden these options bring along. For individual calculations of emission intensity, a method according to $\mathrm{EN}$ 16258:2012 standard will be used. [4,5]

An important point in discussion about transport emissions is to realize that the burden on the environment does not result only from the operation of means of transport, but also from their production and especially from the waste arising from their disposal. Emissions in transport are generated mainly during the chemical processes caused by incomplete combustion. Their composition varies according to the type and condition of the engine, type of fuel used, driving mode, intensity or presence of equipment to reduce emissions (e.g. catalysts). It is estimated that the mass emission unit from motor vehicles transport in city centers is up to 10 times higher than emissions from other sources (heating, industry) and up to 100 times higher than in non-urban areas. Motor vehicles exhaust gases are mixtures of chemicals with various concentrations and with different effect on population. People more sensitive to exhaust gases are children, elderly people and people with cardiovascular or respiratory problems. [6]

\section{European standard EN 16258:2012}

This European standard specifies and describes methodology for calculating and determining energy intensity and volume of GHG emissions in relation to any mode of transport. It can be applied to various modes of transport (road, sea, etc.) as well as for various transported items (passengers, cargo, or both). The method describes in detail general steps, definitions, relations, calculation methods, breakdowns and recommended information as a support of precise and standardized calculation which shows energy intensity and greenhouse gases generation in all modes of transport.

Each calculation of energy intensity and greenhouse gases generation requires necessary volume of information about the specific situation. [7-10]

\footnotetext{
* Corresponding author: luptak@mail.vstecb.cz
} 
Steps in calculating energy consumption and greenhouse gases emissions of one transport service (the 3 following must be included in the calculation):

- step1: Identification of various sections of this transport service

- step 2: Calculation of energy consumption and greenhouse gases emissions in each section

- step 3: Sum of the results from each section.

A great advantage of the standard is the fact that it does not consider only secondary generation of emissions and energy intensity that occurs during the combustion process, that is, extraction of energy from fuel and its transformation into kinetic energy, but also the primary emissions associated with the process of extraction, production and distribution Depending on the type of emissions, the Standard considers the following unknown variables:

- $\mathrm{E}_{\mathrm{w}}$ - well-to-wheels energy factor for the given types of fuel,

- $\mathrm{G}_{\mathrm{w}}$ - well-to-wheels emission factor for the given types of fuel,

- $\mathrm{E}_{\mathrm{t}}$ - tank-to-wheels energy factor for the given types of fuel,

- $\mathrm{G}_{\mathrm{t}}$ - tank-to-wheels wheels emission factor for the given types of fuel. [11]

Well-to-wheels factor includes both primary and secondary emissions including consumption. This factor is sometimes referred to as LCA - "life-cycle analysis" [10]. On the other hand, tank-to-wheels considers only the secondary emissions and consumption. The final calculations of these unknown variables indicate the information on energy consumption and greenhouse gases emissions both in the summing of primary and secondary emissions, and only primary emissions. [1214]

Partial steps of energy consumption and greenhouse gases emissions calculations from one section of a transport service

Calculations for one section of a transport service must be carried out using the following four main steps:

- Partial step 1 - Determining vehicle operation system (VOS) for the given section. For each section of the transport route, it is necessary to start with choosing VOS for a particular section. As a minimum requirement, VOS must be a consistent set of vehicles operation related to a particular section. When determining VOS, the factors influencing the VOS extent and composition (number of vehicles, operation period of these vehicles). Choosing VOS is an optional variable relating to the criteria chosen, but it is necessary to take into account also unladen journeys.

- Partial step 2 - Calculation of the total energy consumption for this particular VOS. For the calculation, the aforementioned category of values is used. If the vehicle uses more types of energy, it is necessary to carry out the calculations for each energy carrier.

- Partial step 3 - Calculation of the total energy consumption and greenhouse gases emissions for this VOS - conversion from the total fuel consumption for VOS to the volume of energy consumed and greenhouse gases emissions must be carried out using the following formulas:

Table 1 Indicators of total energy consumption and greenhouse gases emissions

\begin{tabular}{|l|c|}
\hline \multicolumn{1}{|c|}{ Indicator } & \multicolumn{1}{c|}{ Formula } \\
\hline $\begin{array}{l}\text { for well-to-wheels VOS } \\
\text { energy consumption }\end{array}$ & $E_{w}($ VOS $)=F(V O S) \times e_{w}$ \\
\hline $\begin{array}{l}\text { for well-to-wheels } \\
\text { greenhouse gases VOS } \\
\text { emissions }\end{array}$ & $G_{w}($ VOS $)=F($ VOS $) \times g_{w}$ \\
\hline $\begin{array}{l}\text { for tank-to-wheels VOS } \\
\text { energy consumption }\end{array}$ & $E_{t}($ VOS $)=F(V O S) x e_{t}$ \\
\hline $\begin{array}{l}\text { for tank-to-wheels VOS } \\
\text { greenhouse gases emissions }\end{array}$ & $G_{t}($ VOS $)=F(V O S) \times g_{t}$ \\
\hline $\begin{array}{l}\text { Where: F (VOS) is a total consumption of fuel used for VOS, } \\
\text { ew well-to-wheels energy factor for fuel used, gw well-to- } \\
\text { wheels greenhouse gases emissions for fuel used, et tank-to- } \\
\text { wheels energy factor for fuel used, gt tank-to-wheels } \\
\text { greenhouse gases emissions for fuel used. }\end{array}$ \\
\hline
\end{tabular}

- Partial step 4 - Assigning a share of each of the four results of the partial step to a section - after carrying out steps 1,2,3, the transport service sections must be assigned a share of Ew (VOS), Gw (VOS), Et (VOS), G $\mathrm{t}$ (VOS) corresponding to its relative share of transport activity carried out within VOS.

The relevant formulas are thus as follows:

$S(l e g)=T(l e g) / T(V O S)$

$E w(l e g)=E w(V O S) \times S$ (leg)

$G w(l e g)=G w(V O S) \times S$ (leg)

$E t(l e g)=E t(V O S) \times S$ (leg)

$G t(l e g)=G t(V O S) x S$ (leg)

where:

- S (leg) is a factor used for calculating the energy and emissions share of the VOS assigned to transport service for a particular section. The share is based on the ratio of transport activity for a section and the related VOS,

- T (leg) is a transport activity service for a particular section,

- $\mathrm{T}$ (VOS) is a VOS transport performance in the given field.

- $\mathrm{T}$ (leg) and $\mathrm{T}$ (VOS) must be assigned the same parameters and units. [15]

\section{Application of EN 16258:2012 European standard - Case study}

The main objective of the case study is to determine energy intensity and greenhouse gases emissions for passenger rail transport. After obtaining the results, environmental performance will be assessed according to the European standard and the impact on the environment will be evaluated. The case study will be applied in the relation Jihlava - Brno.

The distance between Jihlava and Brno is $104 \mathrm{~km}$ by rail. The railway car is fully occupied, which means there are 98 passengers. The fuel consumption to gain enough energy to travel the given distance is $59.431 /$ $100 \mathrm{~km}$. The fuel used is diesel. 
Due to the fact that several types $(814,841,842$ and 854 ) of motor railway cars (integrated railway units) are deployed on this particular transport section, thus for objectification within this research study, calculation of the average values of fuel consumption of individual deployed motor units and the average capacity value of individual units are taken into consideration. [16] Consumption of individual units is determined based on the technical parameters and specifications declared by the manufacturer

\section{Step 1. Determining VOS related to section}

First section is a direct route between Jihlava and Brno, railway line No. 240. The distance between the FINAL DESTINATIONS is $104 \mathrm{~km}$, the occupancy rate of the means of transport is $100 \%$.

$$
\operatorname{VOS}\left(1^{\text {st }} \text { section }\right)=104 \mathrm{~km}
$$

\section{Step 2. Calculation of VOS total fuel consumption}

$\mathbf{F}($ VOS $)=$ consumption $\times \mathrm{km}=59.43 \times 1.04=\mathbf{6 1 . 8 0 7 2}$

Step 3. Calculation of total energy consumption and greenhouse gases emissions.

$$
\begin{aligned}
& \boldsymbol{E}_{\boldsymbol{w}}(\boldsymbol{V O S})=F(\text { VOS }) \times e_{w}=61.807 \times 42.7=\mathbf{2 6 3 9 . 1 7} \mathbf{M J} \\
& \boldsymbol{G}_{\boldsymbol{w}}(\boldsymbol{V O S})=F(\operatorname{VOS}) \times g_{w}=61.807 \times 3.24=\mathbf{2 0 0 . 2 6} \\
& \mathrm{kgCO}_{2 e} \\
& \boldsymbol{E}_{\boldsymbol{t}}(\boldsymbol{V O S})=F(\text { VOS }) \times e_{t}=61.807 \times 38.9=2404.3 \mathrm{MJ} \\
& \boldsymbol{G}_{\boldsymbol{t}}(\boldsymbol{V O S})=F(\text { VOS }) \times g_{t}=61.807 \times 2.67=\mathbf{1 6 5 . 0 3} \\
& \mathrm{kgCO}_{2 e}
\end{aligned}
$$

Step 4. Determining share for each section

\begin{tabular}{|c|c|c|c|}
\hline & $\begin{array}{c}\text { Resulting } \\
\text { values of rail } \\
\text { transport } 1^{\text {st }} \\
\text { section (100\% } \\
\text { occupancy) }\end{array}$ & $\begin{array}{c}\text { Resulting } \\
\text { values of rail } \\
\text { transport } 1^{\text {st }} \\
\text { section (50\% } \\
\text { occupancy) }\end{array}$ & $\begin{array}{c}\text { F Resulting } \\
\text { values of rail } \\
\text { transport } 1^{\text {st }} \\
\text { section }(0 \% \\
\text { occupancy) } \\
\end{array}$ \\
\hline Ew(TS) & $26.92 \mathrm{MJ}$ & $80.76 \mathrm{MJ}$ & $2666.09 \mathrm{MJ}$ \\
\hline $\operatorname{Et}(T S)$ & $24.52 \mathrm{MJ}$ & $73.57 \mathrm{MJ}$ & $2428.82 \mathrm{MJ}$ \\
\hline Gw(TS) & $2.04 \mathrm{kgCO} 2 \mathrm{e}$ & $6.13 \mathrm{kgCO} 2 \mathrm{e}$ & $202.30 \mathrm{kgCO} 2 \mathrm{e}$ \\
\hline Gt(TS) & $1.68 \mathrm{kgCO} 2 \mathrm{e}$ & $5.05 \mathrm{kgCO} 2 \mathrm{e}$ & $166.71 \mathrm{kgCO} 2 \mathrm{e}$ \\
\hline
\end{tabular}

$$
\begin{aligned}
& \boldsymbol{S}(\text { leg })=T(\text { leg }) / T(\text { VOS })=(1 \times 104) /(98 \times 104)= \\
& 1.02 \times 10^{-2} \\
& \boldsymbol{E}_{\boldsymbol{w}}(\text { leg })=E_{w}\left(\text { VOS) } \times S(\text { leg })=2639.17 \times 1.02 \times 10^{-2}=\right. \\
& 26.92 M J=E_{w}(T S) \\
& \boldsymbol{G}_{w}(\text { leg })=G_{w}(\text { VOS }) \times S(\text { leg })=200.26 \times 1.02 \times 10^{-2}= \\
& 2.04 \mathrm{kgCO}_{2 e}=G_{w}(T S) \\
& \boldsymbol{E}_{t}(\text { leg })=E t(\text { VOS }) \times S(l e g)=2404.3 \times 1.02 \times 10^{-2}= \\
& \text { 24.52 MJ }=E_{t}(T S) \\
& \boldsymbol{G}_{\boldsymbol{t}}(\mathbf{l e g})=G t\left(\text { VOS) } \times S(\text { leg })=165.03 \times 1.02 \times 10^{-2}=\mathbf{1 . 6 8}\right. \\
& \operatorname{kgCO}_{2 e}=G_{t}(T S)
\end{aligned}
$$

In the same way, the indicators for a $50 \%$ occupancy rate of the vehicle on the relation Brno - Jihlava adding the return route. Table 2 shows the final resulting values of energy consumption and greenhouse gases emissions in the given transport relation. $[13,17]$
Table 2. Final results and impact of number of passengers

The case study deals with the significance of the number of passengers as an aspect influencing final results of energy intensity and greenhouse gases emissions. Before the application, it was not clear what the influence of the number of passengers transported on the calculations and the final result is. For the calculations, two variants of return route were chosen, that differed only in the number of the passengers transported by the means of transport. Using this simulation, it was possible to show a maximum possible impact of the number of passengers, since both maximum and minimum value of the occupancy rate has been included in the calculation. [18] The Table above shows the difference in values caused only by changing the number of passengers transported.

As seen in Table 2 showing all final results analyzed in the study, the number of passengers has a significant influence on final results. Exaggeratedly it can be said that the extreme differences in the values are caused only by the effectiveness the operation of the vehicle was carried out with. The transport was effective if it was able to attract passengers, which resulted in the values on the left-hand side of Table 2, which are significantly lower. The values on the right-hand side are much higher only due to the fact that there were no passengers for a half of the transport route. In principle, the emissions generation and energy intensity of vehicles do not change much. This methodology shows a new direction in thinking and understanding GHG emissions generation from a completely different point of view.

\section{Conclusion}

Lastly, it is necessary to focus on developing proposals, taking into account the study and data processed in the paper, where it is necessary to point out the need for gradual electrification of railway lines in the Czech Republic. In the Czech Republic, there is currently about one third of railway network electrified, which is below average in comparison with Western Europe. Unfortunately, the rail transport in the Czech Republic is not at the required level, and this is also one of the reasons why the share of railway transport in the Czech Republic is also below average.

An important tool for the development of quality public transport, which is the main way of reducing global production of emissions from transport, are also integrated transport systems of territorial units. Simplicity, continuity, but also uniformity of carriers, 
when it is possible to use various modes of transport with one travel pass, this all leads to preference of public transport and reducing congestions and other negatives of heavy traffic in the future.

A possible way to reduce emission gases generation is using alternative power, such as maglev trains or hybrid traction. There are even more options in road transport, ranging from electric engines to hydrogen vehicles. However, it is a fact that many alternative technologies have not been developed enough to represent an equivalent alternative to current modes of transport for acceptable financial investment.

\section{References}

1. E. Demir, W. Burgholzer, M. Hrušovský, E. Arıkan, E., W. Jammernegg, T.V. Woensel, Transportation Research Part B: Methodological, 93, 789-807, (2016)

2. T. Skrucany, S. Semanova, T. Figlus, B. Sarkan, J. Gnap, Communications - Scientific Letters of the University of Zilina, 19, 3-9, 2 (2017)

3. F. Kellner, Energy Policy, 98, 565-575. (2016)

4. F. Kellner, Logistics Research, 9, 1. (2016)

5. T. Skrucany, M. Kendra, M. Skorupa, J. Grencik,T. Figlus, Procedia Engineering, 192. 806 - 811. (2017)

6. F. Cavallaro, F. Maino, V. Morelli, European Transport - Trasporti Europei, 55, (2013)

7. G. Dalkic, O. Balaban, H. Tuydes-Yaman, T. Celikkol-Kocak, Journal of Cleaner Production, 165, 746-761. (2017)

8. G. Fedorko, V. Molnar, J. Strohmandl et al. Transport Means 2015 - Proceedings of the International Conference. 466-+ (2015)
9. T. Kirschstein, F. Meisel, Transportation Research Part B: Methodological, 73, 13-33, (2015)

10. M. Mohsen, M.B. Ahmed, J.L. Zhou, Transportation Research Part D: Transport and Environment, 62, 112-124, (2018)

11. Y. Ge,.J. Long, F. Xiao, Q. Shi, Transportation Research Part D: Transport and Environment, 60, 16, (2018)

12. F. .Ma, W. Wang, Q. Sun, F. Liu, X. Li, Sustainability (Switzerland), 10, 2 (2018)

13. A. Galierikova, J. Sosedova. Ekologia:35, 3. 279288, (2016)

14. A. Torok. Transport 24, 26-29, (2009) DOI: 10.3846/1648-4142.2009.24.26-29

15. W. Yang, S. Wang, X. Zhao, Sustainability (Switzerland), 10, 5 (2018)

16. V. Hromadka, E. Vítkova, H. Kovarova, P. Vařbuchta, International Multidisciplinary Scientific GeoConference Surveying Geology and Mining Ecology Management, SGEM, (2014)

17. M. Kendra, 1st International Conference on Engineering and Applied Sciences Optimization, Proceedings, (2014)

18. MM. Zefreh, F. Meszaros, R. Junevicius, A. Torok. Promet-Traffic\&Transportation, 29,1, 77-84, 10.7307/ptt.v29i1.2072

19. M. Vojtek, M. Kendra, V. Zitricky, J. Danis, MATEC Web of Conferences, 134, 00061, (2017)

20. L. Hansut, A. David, J. Gasparik. Bussines Logistic In Modern Management. 29-42. (2017) 